\title{
The Linear Fokker-Planck Equation for the Ornstein-Uhlenbeck Process as an (Almost) Nonlinear Kinetic Equation for an Isolated N-Particle System
}

\author{
Michael Kiessling • Carlo Lancellotti
}

Published online: 1 December 2007

(C) Springer Science+Business Media, LLC 2007

\section{Erratum to: J Stat Phys}

DOI: $10.1007 / \mathrm{s} 10955-006-9057-3$

Copyright for the article "The Linear Fokker-Planck Equation for the OrnsteinUhlenbeck Process as an (Almost) Nonlinear Kinetic Equation for an Isolated N-Particle System", by Michael Kiessling and Carlo Lancellotti, was mistakenly designated as belonging to the Publisher in the article, published online 10 June 2006 and included in Volume 123, Issue 3, May 2006.

Copyright of the article remains with the authors.

The online version of the original article can be found under doi: 10.1007/s10955-006-9057-3.

\footnotetext{
M. Kiessling

Department of Mathematics, Rutgers University, Piscataway, NJ 08854, USA

C. Lancellotti

Department of Mathematics, City University of New York-CSI, Staten Island, NY 10314, USA
} 